\title{
Heteronuclear Metal-organic Frameworks; Adsorption and Luminescence Aspects
}

\author{
MUHAMMAD IMRAN ${ }^{1 *}$, FARAH KANWAL ${ }^{1}$, SHOOMAILA LATIF ${ }^{2}$, ZAFAR IQBAL ${ }^{3}$, \\ LIVIU MITU** \\ ${ }^{1}$ Institute of Chemistry, Punjab University, Lahore, Pakistan \\ ${ }^{2}$ Department of Chemistry, University of Lahore, Pakistan \\ ${ }^{3}$ Department of Chemistry, Lahore University of Management and Sciences, Pakistan \\ ${ }^{4}$ Department of Nature Sciences, University of Pitesti, 1 Targu din Vale Str., 110040, Pitesti, Romania
}

Abstract. Synthesis of heteronuclear metal organic frameworks (1 \& 2) using 4-mercaptobenzoic acid ( $\left.\mathrm{H}_{2} \mathrm{MBA}\right)$ and 2,6-naphthalenedicarboxylic acid (2,6-NDA) was carried out followed by successful characterization with FTIR, SEM, EDX, ${ }^{1} H$-NMR, TGA and PXD. Brunauer-Emmett-Teller (BET) and luminescence studies of these MOFs were also investigated.

Keywords: Bidentate ligand, Bismuth, Lead, Luminescence, Metal-organic frameworks

\section{Introduction}

Metal-organic frameworks (MOFs) have lead to innumerable research and gained attention in the scientific fields like chemistry, physics, materials science and other bordering research areas, etc [1]. These MOFs have potentially accessible voids, which make them ideal materials for a wide range of uses like gas storage, separation and catalysis [2]. Recently, metal-organic frameworks (MOFs) were used as adsorbents due to having unique textural properties that could be determined by analysis of their isotherms. Brunauer, Demming, Demming, and Teller (BDDT) categorized these adsorption isotherms into five types [3,4] The design, structure and properties of these MOFs can be tuned by modifying organic linkers [5].

Current direction is to design heterometallic or mixed-metal MOFs that contain different metal cations. Initially simple bimetallic MOFs were obtained by combination of coordination complexes (acting as a secondary building unit, or SBU) with a metal salt to construct 3D frameworks [6-8]. Complex heterometallic MOFs have also been reported recently and contain larger number of cations, or two types of SBUs [9]. However, a detailed description and characterization of these heterometallic systems in different applications is still superficial.

The representation of the different functional groups in the multifunctional MOFs is very hard to be determined [10]. Recently, synthesis and characterization of a multivariate MOFs such as the $\mathrm{AlPO}_{4}$ $[11,12]$, alkali metal-lanthanide carboxylates [13-16] and lithium-boron series of zeolitic imidazolate frameworks [17-19] has been reported.

Keeping in view recent trends towards heteronuclear MOFs, in this paper, we report the synthesis, morphological, luminescence and gas adsorption studies of two heteronuclear MOFs (1 \& 2) using 4mercaptobenzoic acid ( $\left.\mathrm{H}_{2} \mathrm{MBA}\right)$ and 2,6-naphthalenedicarboxylic acid (2,6-NDA) as organic linkers.

\section{Materials and methods}

Required chemicals (4-mercaptobenzoic acid, 2,6-naphthalenedicarboxylic acid, bismuth chloride and lead nitrate (Sigma-Aldrich and Uni-chem) were of reagent grade. Decomposition points were determined by Gallenkamp apparatus. The FT-IR spectra were recorded by Cary 630 FTIR Agilent Technologies and ${ }^{1} \mathrm{H}-\mathrm{NMR}$ spectra were recorded on Avance AV-400 spectrometers. The morphological features were investigated by Scanning electron microscope (SEM, Inspect S50, FEI,

\footnotetext{
$\overline{\text { *email: imran_inorganic@yahoo.com;ktm7ro@yahoo.com }}$
} 
USA) and energy-dispersive X-ray spectroscopy (EDS) was carried out by using EDAX system (Ametek, Inc. Materials Analysis Division, USA). TGA was done by SDT Q600 instrument (range $30^{\circ}$ to $800^{\circ} \mathrm{C}$, heating rate of $10^{\circ} \mathrm{C} / \mathrm{min}$ ). Diffractometer (Equinox 2000, Thermoscientific, USA, $\mathrm{CuK} \alpha_{1}$ radiation) was used to obtain diffraction patterns. BET analysis was completed by using Tri Star II 3020 version 2.00. Luminescence spectra were recorded by using PerkinElmer multimode plate reader at excitation wavelength $320 \mathrm{~nm}$.

\subsection{Synthesis of MOF (1)}

$\mathrm{BiCl}_{3}\left(1.0 \mathrm{mmol}, 0.40 \mathrm{~g}, 15 \mathrm{~mL}\right.$ acetonitrile/1 mL DMF), $\mathrm{Pb}\left(\mathrm{NO}_{3}\right)_{2}\left(1 \mathrm{mmol}, 0.30 \mathrm{~g}, 10 \mathrm{~mL} \mathrm{H}{ }_{2} \mathrm{O} / 1\right.$ $\mathrm{mL} \mathrm{DMF})$ and 4-mercaptobenzoic acid $(0.20 \mathrm{~g}, 1.0 \mathrm{mmol}, 5 \mathrm{~mL} \mathrm{CH} 3 \mathrm{OH})$ were mixed together and stirred for $4 \mathrm{hrs}$ at room temperature. The resulting solutions were concentrated and the precipitates formed were filtered off, washed with methanol ( $3 \mathrm{~mL}$, thrice) and finally dried. The precipitates were kept in desiccator for further use. Precipitates (orange colored); Yield, $68 \%$; D.P.: > 300 ${ }^{\circ}$ C; FT-IR $\left(\mathrm{cm}^{-1}\right): v\left(\mathrm{COO}_{\text {asym }}\right) 1557 \mathrm{~cm}^{-1}, v\left(\mathrm{COO}_{\text {sym }}\right) 1392 \mathrm{~cm}^{-1}, v \mathrm{C}=\mathrm{S} 1010 \mathrm{~cm}^{-1} ;{ }^{1} \mathrm{H}-\mathrm{NMR}\left(400 \mathrm{MHz}, \mathrm{dmso}-d_{6}\right)$ : $\delta=7.38-7.68(\mathrm{~m}, 4 \mathrm{H}, \mathrm{Ar}-\mathrm{H})$.

\subsection{Synthesis of MOF (2)}

$\mathrm{BiCl}_{3}\left(1 \mathrm{mmol}, 0.40 \mathrm{~g}, 10 \mathrm{~mL}\right.$ acetonitrile/1 mL DMF), $\mathrm{Pb}\left(\mathrm{NO}_{3}\right)_{2}\left(1 \mathrm{mmol}, 0.30 \mathrm{~g}, 10 \mathrm{~mL} \mathrm{H} \mathrm{H}_{2} \mathrm{O}\right.$ $\mathrm{mL} \mathrm{DMF})$ and 2,6-naphthalenedicarboxylic acid (1.0 mmol, $0.30 \mathrm{~g}, 15 \mathrm{~mL} \mathrm{DMF})$ were mixed together and stirred for $4 \mathrm{hrs}$ at room temperature. During the course of stirring, colorless precipitates formed were filtered off, washed with methanol and acetonitrile $(3 \mathrm{~mL}$, thrice) and finally dried. The precipitates were kept in desiccator for further use. Precipitates (colorless); Yield, $62 \%$; D.P.: > $300^{\circ} \mathrm{C}$; FT-IR $\left(\mathrm{cm}^{-1}\right): v\left(\mathrm{COO}_{\text {asym }}\right) 1508 \mathrm{~cm}^{-1}, v\left(\mathrm{COO}_{\text {sym }}\right) 1397 \mathrm{~cm}^{-1} ;{ }^{1} \mathrm{H}-\mathrm{NMR}\left(400 \mathrm{MHz}, \mathrm{dmso}-d_{6}\right): \delta$ $=8.02-8.65(\mathrm{~m}, 4 \mathrm{H}, \mathrm{Ar}-\mathrm{H}), \delta=2.87(\mathrm{~d}, 3 \mathrm{H}$,

$\left.-\mathrm{CH}_{3}\right)$.

\section{Results and discussions}

Heteronuclear MOFs $(\mathbf{1} \& \mathbf{2})$ were obtained in good yields $(62-68 \%)$ by reacting bismuth and lead salts with respective organic linker. MOF (1) was orange colored while MOF (2) was colorless. Both the MOFs were air stable solids and soluble only in DMSO suggesting that they possess polymeric or aggregated framework structure.

The bonding modes of $\mathrm{H}_{2} \mathrm{MBA}$ and $\mathrm{H}_{2} \mathrm{NDA}$ with mixed metal ions were established by comparing FT-IR spectra of MOFs (1) \& (2) with free linkers i.e $\mathrm{H}_{2} \mathrm{MBA}$ and $\mathrm{H}_{2} \mathrm{NDA}$. The FT-IR spectra exhibited the presence of strong absorption peaks between $1557-1392 \mathrm{~cm}^{-1}$ for (1) and $1508-1397 \mathrm{~cm}^{-}$ 1 for (2). This can be attributed to the asymmetric and symmetric COO stretching vibrations, respectively. The separations $(\Delta v)$ between $v_{\text {asym }}(\mathrm{COO})$ and $v_{\text {sym }}(\mathrm{COO})$ were found to be $165 \mathrm{~cm}^{-1}$ and $111 \mathrm{~cm}^{-1}$ indicating coordination through carboxylate group via monoanionic bidentate mode [20]. A shift of band was found at $1010 \mathrm{~cm}^{-1}$ in MOF (1) $\left(1099 \mathrm{~cm}^{-1}\right.$ for $\mathrm{H}_{2} \mathrm{MBA}$ linker) which indicates the coordination through $\mathrm{C}=\mathrm{S}$ group as well. ${ }^{1} \mathrm{H}-\mathrm{NMR}$ spectra of MOFs $(\mathbf{1} \& \mathbf{2})$ were recorded in DMSO$d_{6}$ and are represented in (Figures $1 \& 2$ ). These spectra lack the presence of $-\mathrm{COOH}$ signal thus indicating deprotonation and subsequent coordination with $\mathrm{Bi}^{+3}$ and $\mathrm{Pb}^{+2}$ ions [21, 22]. The other signals such as multiplets in the region 7.31-7.68 ppm for (1) and 8.02-8.65 ppm for (2), assigned to protons of aromatic rings, are in agreement with proposed structures. 


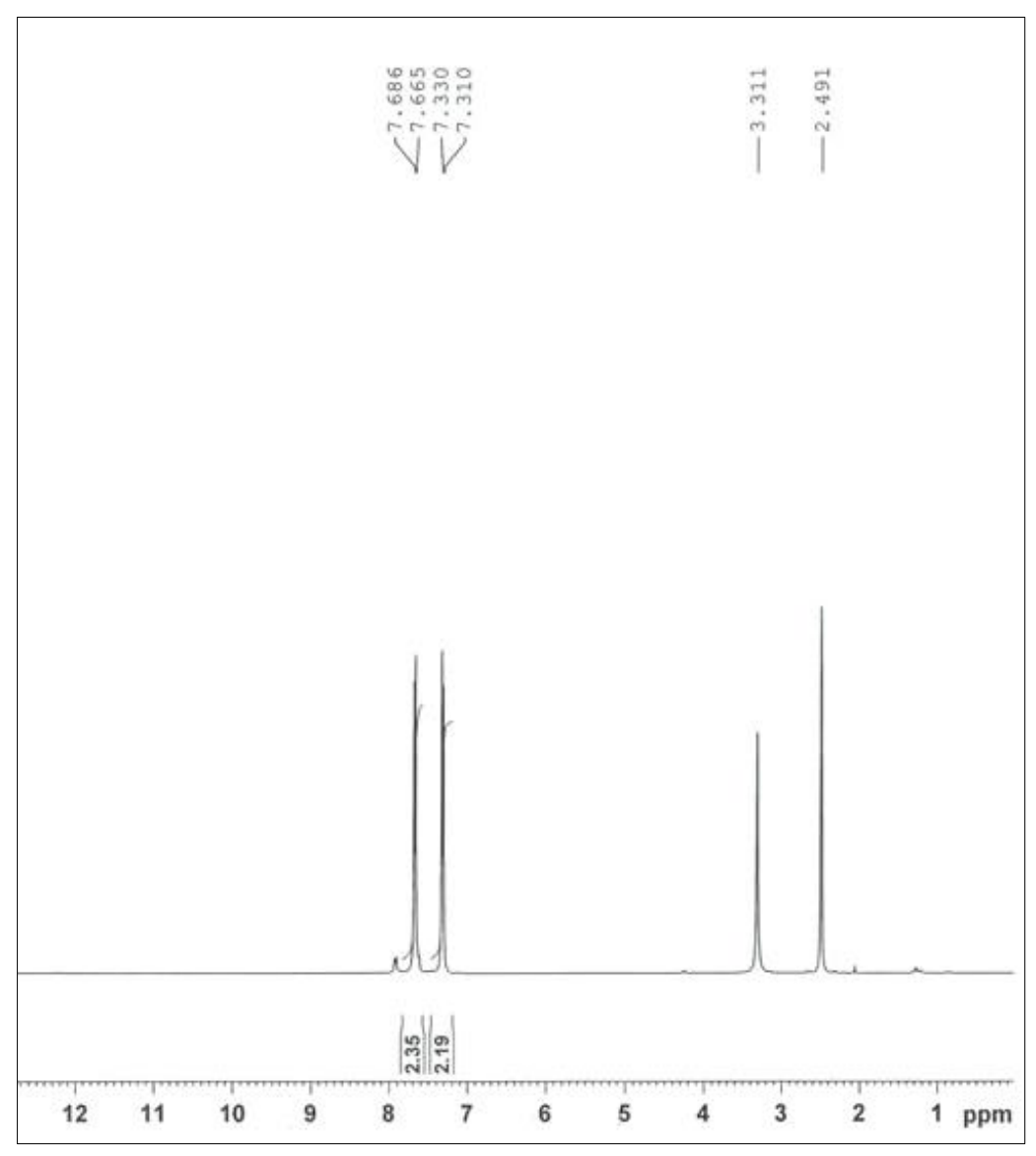

Figure 1. ${ }^{1} \mathrm{H}-\mathrm{NMR}$ spectrum of heteronuclear $\operatorname{MOF}(\mathbf{1})$

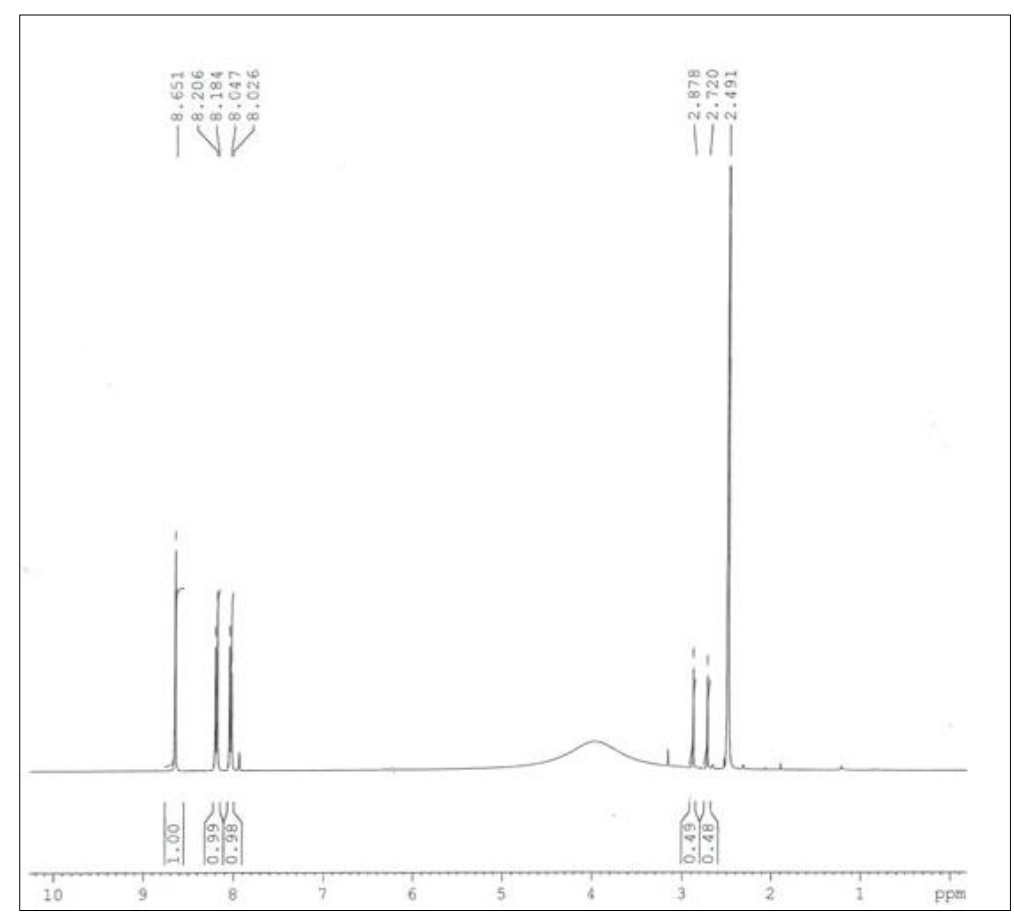

Figure 2. ${ }^{1} \mathrm{H}-\mathrm{NMR}$ spectrum of heteronuclear MOF (2)

\subsection{Powder X-ray diffraction studies}

$\mathrm{X}$-ray powder diffraction is very useful to learn about crystal structure, phase type and material purity. Powder X-ray diffraction patterns of MOFs (1) and (2) are shown in (Figures $3 \& 4$ ). These heteronuclear MOFs were less crystalline than the homonuclear Pb-MBA and Bi-NDA MOFs [23, 24]. 
No contributions of other crystalline phases (in addition to $\mathrm{Bi}$ and $\mathrm{Pb}$-containing phases) was detected in the diffraction patterns.

The main diffraction peaks for heteronuclear MOF $(\mathbf{1})$ were observed at $2 \theta=11.15^{\circ}, 19.17^{\circ}, 22.37^{\circ}$ and $28.95^{\circ}$ and were indexed with monoclinic $(C 12 / \mathrm{ml})$ system having unit cell parameters $(\mathrm{a}=$ $6.6726 \AA, b=6.1108 \AA, c=3.3001 \AA, \beta=110.412^{\circ}$ ).

The main peaks for MOF (2) were observed at $2 \theta=16.70^{\circ}, 31.83^{\circ}, 37.34^{\circ}, 43.65^{\circ}$ indexed with orthorhombic (Pbcn) system haiving unit cell parameters $(\mathrm{a}=18.5800 \AA, \mathrm{b}=13.1810 \AA$, c $=8.6000$ $\AA$ ). Generally, the peaks positions of the high intensity peaks in heteronulcear MOFs (1) \& (2) were shifted to a small extent as observed in the patterns of homonuclear Pb-MBA $\left(9.38^{\circ}\right)$ and $\mathrm{Bi}-\mathrm{NDA}$ $\left(26.00^{\circ}\right)[23,24]$.

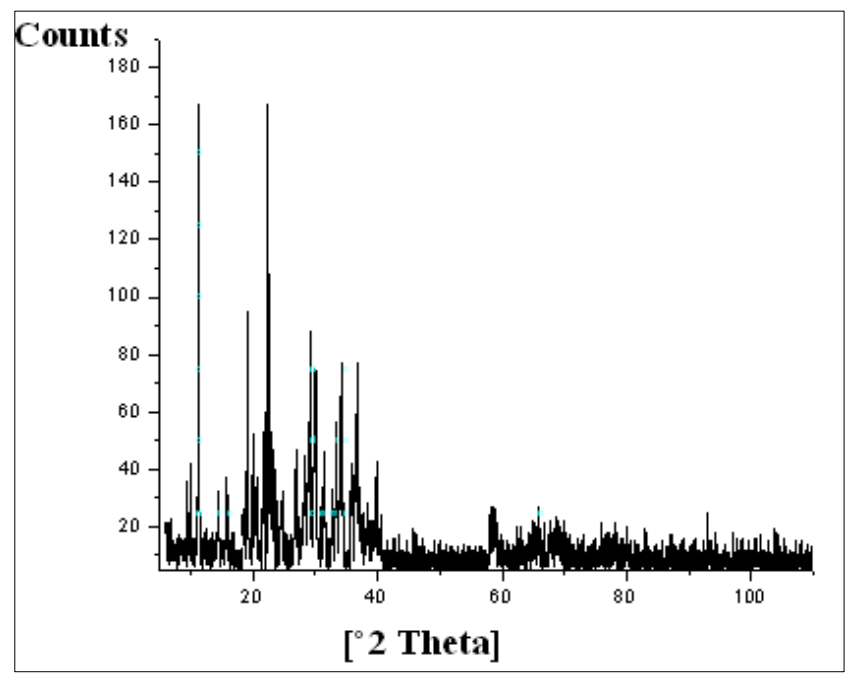

Figure 3. Powder X-ray diffraction (PXRD) pattern of MOF (1)

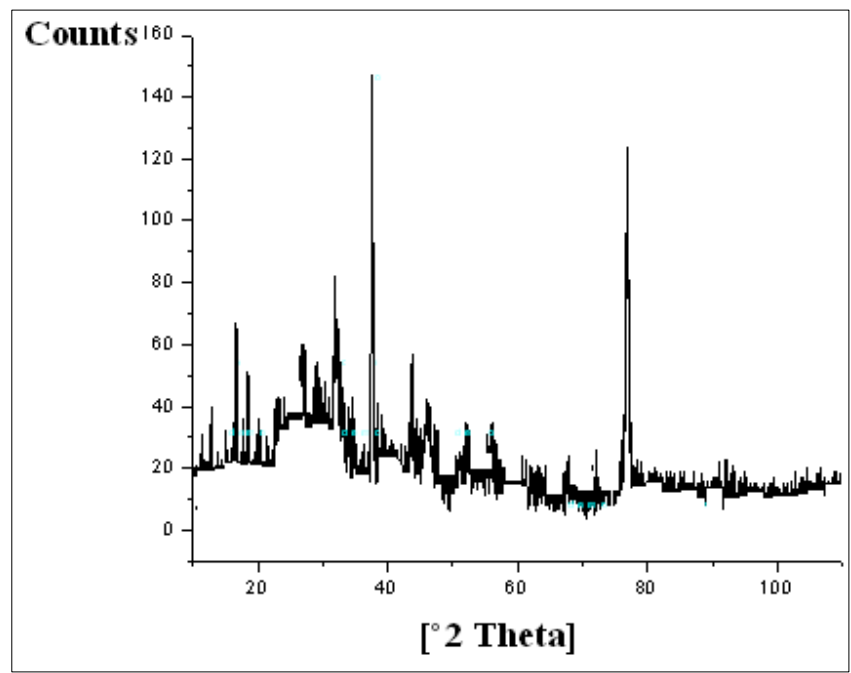

Figure 4. Powder X-

ray diffraction

(PXRD) pattern of MOF (2)

\subsection{Scanning electron microscopy and EDS}

The morphologies of these MOFs (1 \& 2) were analyzed by SEM and their micrographs are shown in (Figures 5a \& 6a). The SEM image of the MOF (1) displayed homogeneous irregular nanocrystallites aggregated clusters and is comparable to the morphology of MM-MOF-74 $\left[\mathrm{M}_{2}\right.$ (DOT); DOT = dioxidoterephthalate] [25]. The SEM image of MOF (2) displayed irregular shaped particles. These images clearly illustrated that the incorporation of two different metal ions lead to significant changes in their morphology which was observed in case of homonuclear Pb-MBA and Bi-NDA MOFs [23, 24]. 
The chemical composition of MOFs (1) and (2) was studied by EDS and the spectra are presented in (Figures $5 \mathrm{~b} \& 6 \mathrm{~b}$ ). Quantitative analysis of the EDX (1) revealed the existence of bismuth (33.35 wt $\%)$, lead (22.86 wt \%), carbon (19.54 wt \%), oxygen (13.66 wt \%) and sulphur (10.59 wt \%). Similarly, EDX spectrum of (2) showed the existence of bismuth (28.24 wt \%), lead (24.03 wt \%) and oxygen (14.83 wt \%). These results clearly depicted the incorporation of both bismuth and lead metal ions into the organic framework thus confirming the successful synthesis of heteronuclear MOFs $(1 \&$ 2).
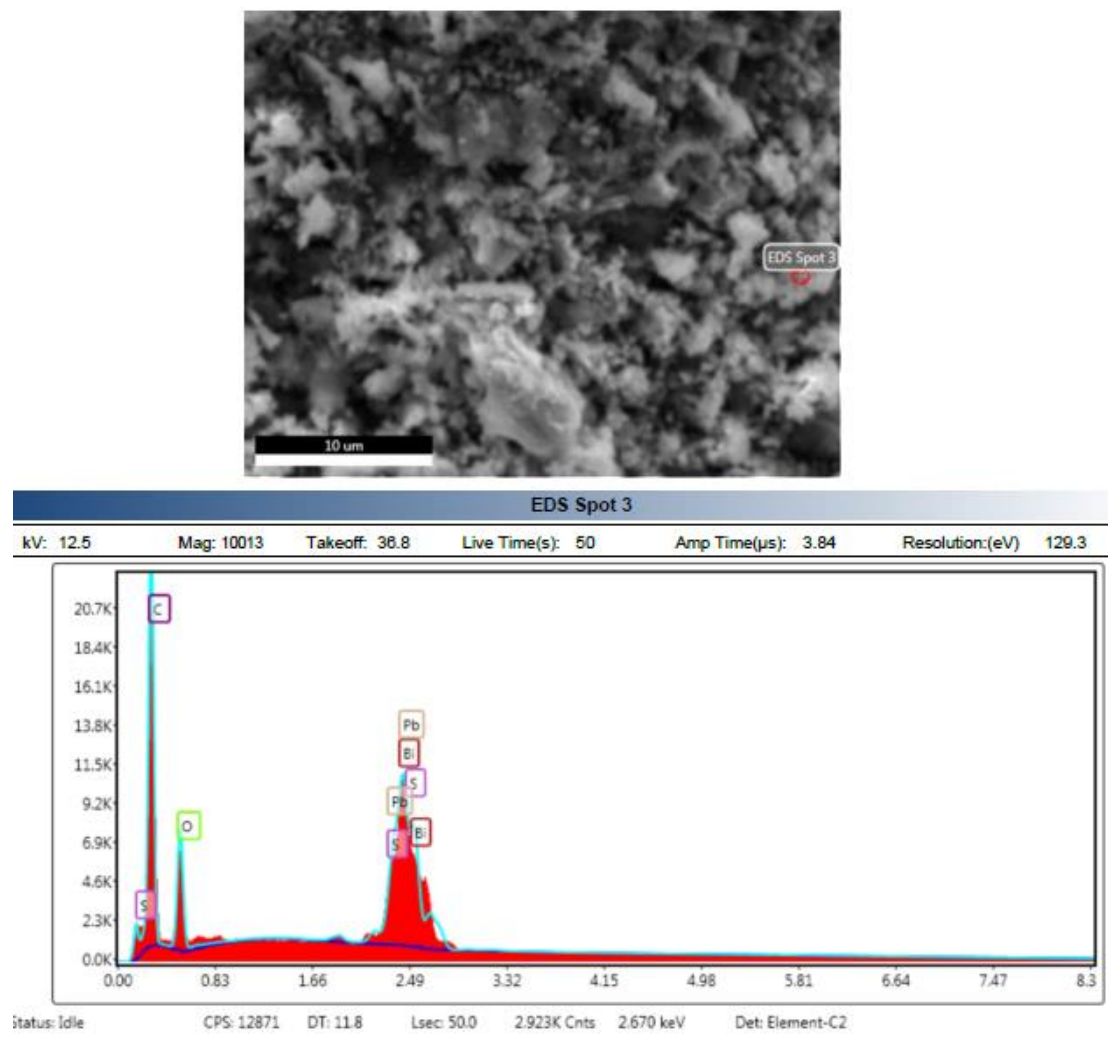

Figure 5. (a) SEM image and (b) EDS of heteronuclear MOF (1)
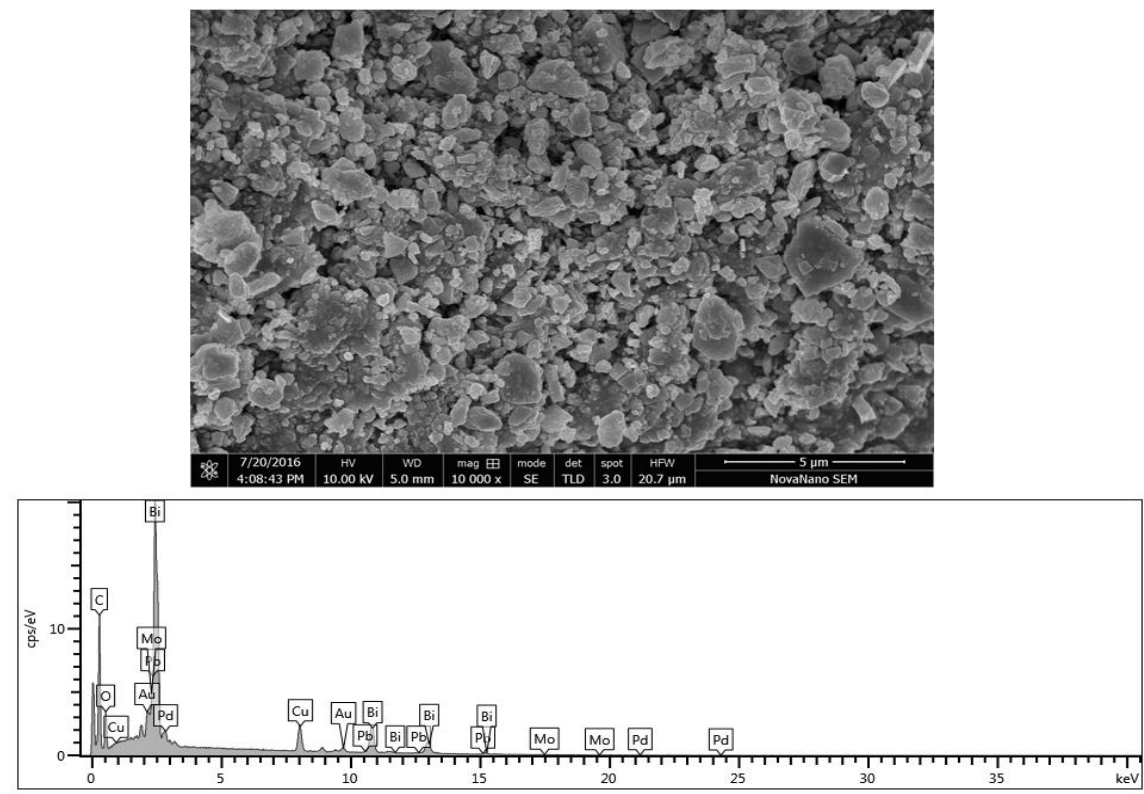

Figure 6. (a) SEM image and (b) EDS of heteronuclear MOF (2) 


\subsection{Thermal gravimetric analysis}

Thermal gravimetric analysis of heteronuclear MOFs $\left(\begin{array}{l}1 \\ \mathbf{1}\end{array} \mathbf{2}\right)$ were carried out to check their thermal stability and the respective TGA curves are presented in (Figure 7). Initial weight loss was observed between $50-150^{\circ} \mathrm{C}$ in both MOFs and can be attributed to the release of the hydrated water and methanol molecule. Second decomposition was observed in the range $200-250^{\circ} \mathrm{C}$ for (1) and 215$300^{\circ} \mathrm{C}$ for (2) corresponding to the release of DMF molecule [26]. Further decomposition started at $250^{\circ} \mathrm{C}$ for $(1)$ and at $300^{\circ} \mathrm{C}$ for (2). This goes up to $520^{\circ} \mathrm{C}$ and then the curve becomes almost flat leading to formation of respective metal oxide.

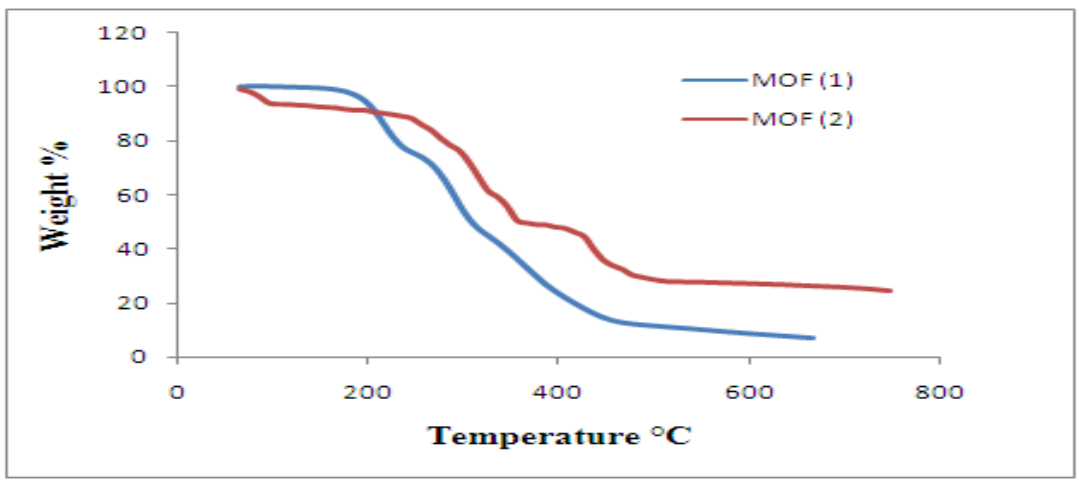

Figure 7. TGA curves of heteronuclear MOFs $(\mathbf{1} \& \mathbf{2})$

\subsection{Photo-physical studies}

Luminescence properties of heteronuclear MOFs $(\mathbf{1} \&$ 2) were studied in solid state at room temperature. The data obtained is graphically represented in (Figures 8 and 9).

Both these MOFs exhibited emissions at $427 \mathrm{~nm}(\mathbf{1})$ and $476 \mathrm{~nm}$ (2) relative to homonuclear PbMBA $(425 \mathrm{~nm})$ and Bi-NDA $(438 \mathrm{~nm}$ and $476 \mathrm{~nm})[23,24]$. The emission intensities of both these MOfs are also different. These could be attributed to intraligand luminescence, $\left(\mathrm{n} \leftarrow \pi^{*}\right)$ or $\left(\pi \leftarrow \pi^{*}\right)$ transitions and are also comparable with related reported Sodium-Bismuth benzene dicarboxylates MOFs [27].

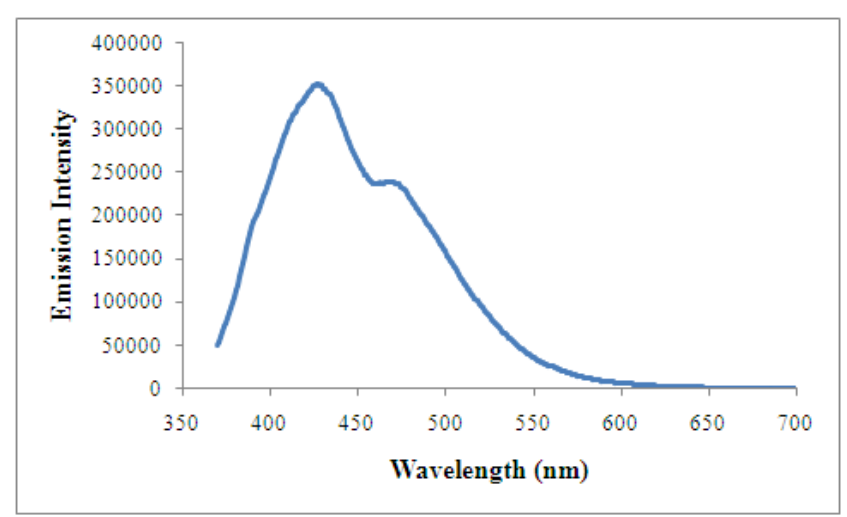

Figure 8. Luminescence behavior of heteronuclear MOF (1)

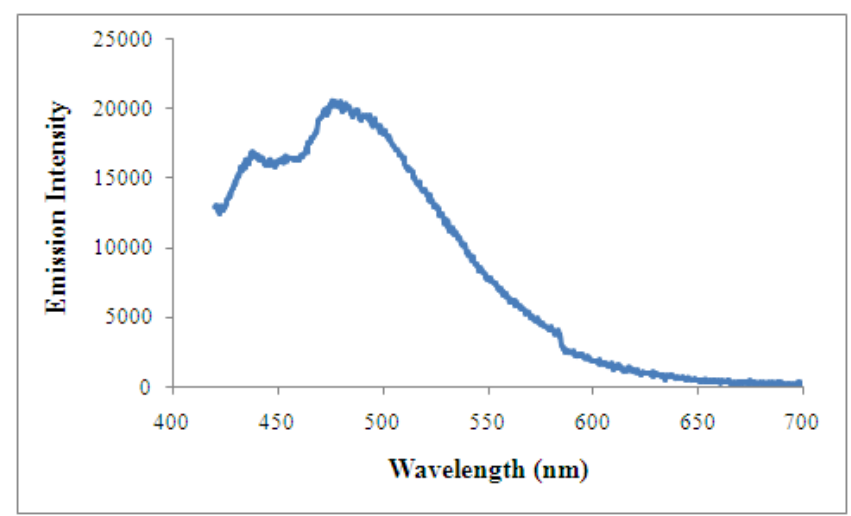

Figure 9. Luminescence behavior of heteronuclear MOF (2)

\subsection{Surface Area and Porosity Characterization}

(Figs. 10-13) demonstrate $\mathrm{N}_{2}$ adsorption isotherms/BET analysis of heteronuclear MOFs $(\mathbf{1} \& \mathbf{2})$, respectively. These isotherms are Type II according to the BDDT classification. However, a significantly lower surface area $681 \mathrm{~m}^{2} / \mathrm{g}$ for (1) and $1096 \mathrm{~m}^{2} / \mathrm{g}$ for (2) were oberved compared to homonuclear Pb-MBA and Bi-NDA MOFs (S $\mathrm{S}_{\mathrm{BET}}$ : $742 \mathrm{~m}^{2} / \mathrm{g}$ and $1414 \mathrm{~m}^{2} / \mathrm{g}$ ) [23, 24]. Similar observations of lower surface area were observed for heteronuclear $\mathrm{Cu}-\mathrm{Zn}-\mathrm{BTC}\left(\mathrm{S}_{\mathrm{BET}}: 830 \mathrm{~m} / \mathrm{g}\right)$ and 
Cu-Ru-BTC ( S $_{\text {BET: }} 530 \mathrm{~m}^{2} / \mathrm{g}$ ) MOFs $[28,29]$. The size difference of $\mathrm{Bi}^{3+}$ and $\mathrm{Pb}^{2+}$ ions can cause disorder of the lattice that provides a reasonable explanation for the reduced porosity of both MOFs.

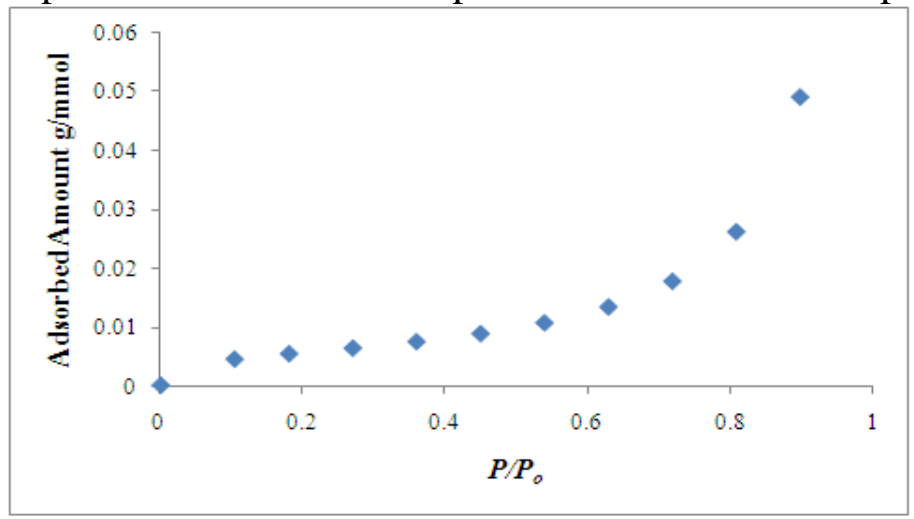

Figure 10. $\mathrm{N}_{2}$ adsorption at $77.300 \mathrm{~K}$ on heteronuclear MOF (1)

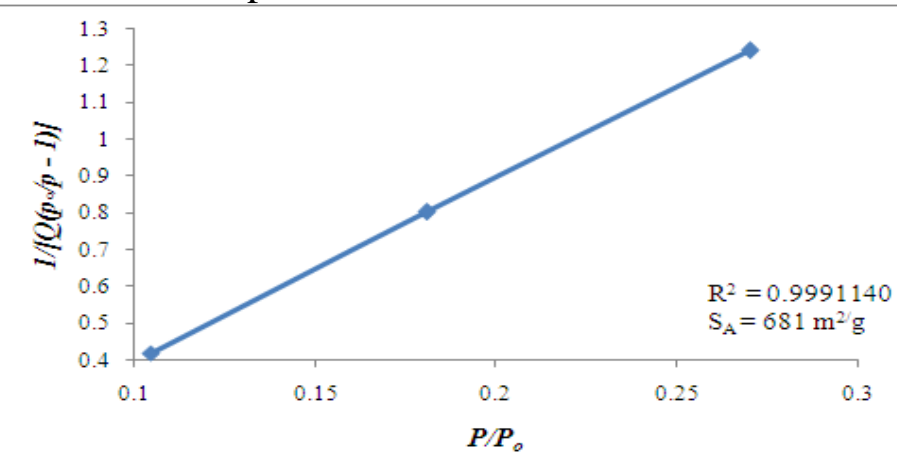

Figure 11. BET analysis of heteronuclear MOF (1)

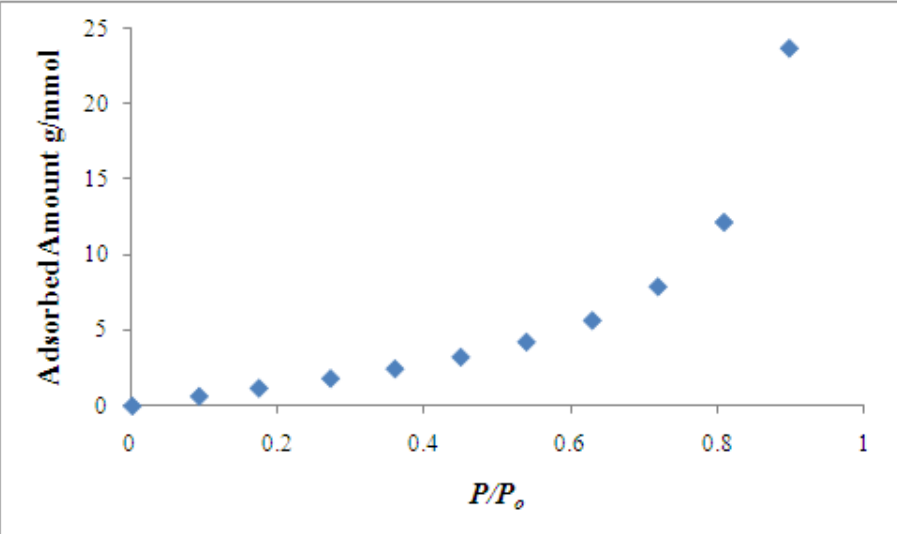

Figure 12. $\mathrm{N}_{2}$ adsorption at 77.300 K on heteronuclear MOF (2)

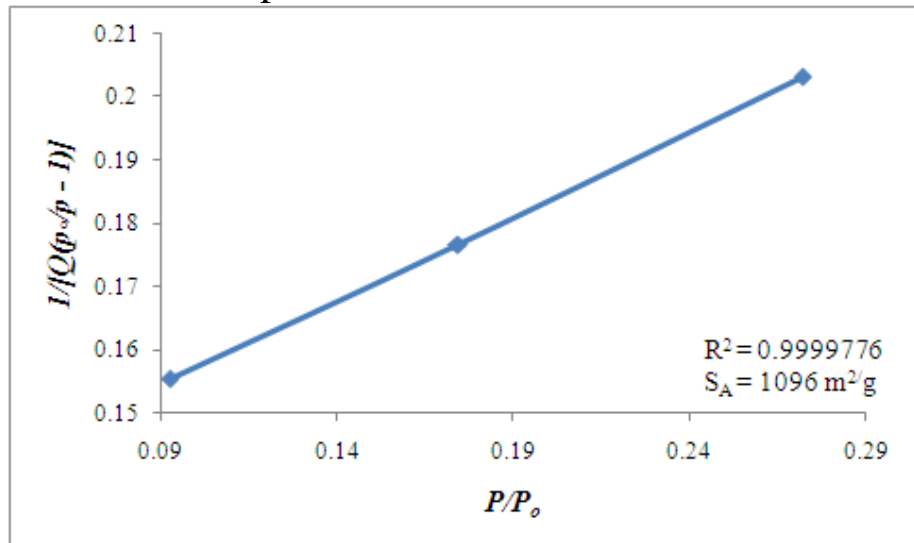

Figure 13. BET analysis of heteronuclear MOF (2) 


\section{Conclusions}

In this paper, two heteronuclear MOFs have been synthesized and structurally characterized. MOF

(1) exhibited very appreciable luminescence than MOF (2) and could be considered as promising material in light devices. Moreover, these MOFs could also be considered as effective adsorbents for nitrogen gas as well as for other pollutants due to their better pore textural properties.

\section{References}

1. ZHOU, H.C., KITAGAWA, S., Metal-organic frameworks (MOFs), Chem.Soc.Rev., 43(16), 2014, 5415-5418.

2. FARHA, O.K., ERYAZICI, I., JEONG, N.C., HAUSER, B.G., WILMER, C.E.,

SARJEANT, A.A., SNURR, R.Q., NGUYEN, S.T., YAZAYDIN, A.O., HUPP, J.T., Metal-organic framework materials with ultrahigh surface areas: is the sky the limit?, J.Am.Chem.Soc., 134(36), 2012, 15016-15021.

3. BRUNAUER, S., DEMING, L.S., DEMING, W.E., TELLER, E., J.Am.Chem.Soc., 62, 1940, 1723.

4. GREGG, S.J., SING, K.S.W., Adsorption, Surface Area and Porosity, Academic Press Inc.Ltd., London, 1982, 957.

5. IRAM, S., IMRAN, M., KANWAL, F., LATIF, S., IQBAL, Z., Lead Based Metal Organic Frameworks (Pb-MOFs): Anion Influence, Luminescence and Gas Adsorption Study, Rev. Chim., 70(10), 2019, 3545-3548.

6.HE,J., YU,J., ZHANG,Y., PAN,Q., XU,R., Synthesis, Structure and Luminisant Property of hetrometallic metal organic Framework constructed from rod shaped building block, Inorg.Chem., 44(25), 2005, 9279-9282.

7.HALPER, S.R., COHEN, S.M., Heterometallic metal-organic frameworks based on tris (dipyrrinato) coordination complexes, Inorg.Chem., 44(3), 2005, 486-488.

8.MURPHY, D.L., MALACHOWSKI, M.R., CAMPANA, C.F., COHEN, S.M., A chiral, heterometallic metal-organic framework derived from a tris (chelate) coordination complex,

Chem.Commun., 44, 2005, 5506-5508.

9. ZOU, R., LI, P.Z., ZENG, Y.F., LIU, J., ZHAO, R., DUAN, H., LUO, Z., WANG, J.G.,

ZHAO, Y., Bimetallic Metal-Organic Frameworks: Probing the Lewis Acid Site for CO2 Conversion, Small., 12(17), 2016, 2334-2243.

10. KONG, X., DENG, H., YAN, F., KIM, J., SWISHER, J.A., SMIT, B., YAGHI, O.M., REIMER, J., Mapping of functional groups in metal-organic frameworks, Scien., 341(6148), 2013, 882-885.

11.CHEETHAM, A.K., FEREY, G., LOISEAU, T., Open-framework inorganic materials, Angew.Chem.Int.Ed., 38(22), 1999, 3268-3292.

12. MURUGAVEL, R., CHOUDHURY, A., WALAWALKAR, M.G., POTHIRAJA, R.,

RAO, C.N.R., Metal complexes of organophosphate esters and open-framework metal phosphates: synthesis, structure, transformations, and applications, Chem.Rev., 108(9), 2008, 3549-3655.

13. LONG, L.S., HU, J.Y., REN, Y.P., SUN, Z.G., HUANG, R.B., ZHENG, L.S., Main Group, Metal.Chem., 25, 2002, 749.

14. CANADILLAS-DELGADO, L., FABELO, O., RUIZ-PEREZ, C., DELGADO, F.S., JULVE, M., HERNÁNDEZ-MOLINA, M., LAZ, M.M., LUIS, P.L., Zeolite-like

Nanoporous Gadolinium Complexes Incorporating Alkaline Cations, Cryst.Growth Des., 6, 2006, 87-93.

15. CANADILLAS-DELGADO, L., PASAN, J., FABELO, O., HERNANDEZ-MOLINA, M., LLORET, F., JULVE, M., RUIZ-PEREZ, C., Two-and three-dimensional networks of gadolinium(III) with dicarboxylate ligands: synthesis, crystal structure, and magnetic properties, Inorg. Chem., 45(26), 2006, 10585-10594.

16. YING-XIA, Z., XIAO-QING, S., CHEN-XIA, D., BEN-LAI, W., HONG-YUN, Z., 
1D, 2D and 3D Coordination Polymers of Aromatic Carboxylate $\mathrm{Tb}^{\mathrm{III}}$ : Structure, Thermolysis Kinetics and Fluorescence, Eur.J.Inorg.Chem., 2008(27), 2008, 4280-4289.

17.ZHANG, J., WU, T., ZHOU, C., CHEN, S., FENG, P., BU, X., Zeolitic boron imidazolate frameworks, Angew.Chem.Int.Ed., 48(14), 2009, 2542-2545.

18.WU, T., ZHANG, J., ZHOU, C., WANG, L., BU, X., FENG, P., Zeolite RHO-type net with the lightest elements, J.Am.Chem.Soc., 131(17), 2009, 6111-6113.

19.WU, T., ZHANG, J., BU, X., FENG, P., Variable lithium coordination modes in two-and threedimensional lithium boron imidazolate frameworks, Chem.Mater., 21(16), 2009, 3830-3837.

20. SAHU, J., AHMAD, M., BHARADWAJ, P.K., Structural diversity and luminescence properties of coordination polymers built with a rigid linear dicarboxylate and $\mathrm{Zn}$ (II)/Pb (II) ion, Cryst.Growth Des., 13(6), 2013, 2618-2627.

21.SINGH, K., KUMAR, V., Spectral, Thermal, Fluorescence and Antimicrobial Studies of Some Newly Synthesized Metal Complexes Having 1,2,4-Triazine Moiety, J.Chem.Bio.Phys.

Scien., 5(3), 2015, 2691-2705.

22. MARKLEY, T.J., TOBY, B.H., PEARLSTEIN, R.M., RAMPRASAD, D., New synthesis routes to lithium and cesium cyanide salts, Inorg. Chem., 36(15), 1997, 3376-3378.

23. SHAMAILA, I., MUHAMMAD, I., FARAH, K., SHOOMAILA, L., ZAFAR, I., Morphological, luminescence and gas adsorption studies of $\mathrm{Pb}(\mathrm{II})-\mathrm{MOFs}$, Mater. Res.Express., 6(2), 2019, 025103.

24. SHAMAILA, I., MUHAMMAD, I., FARAH, K., ZAFAR, I., FARAH, D., QAZI, J.I.,

Bismuth(III) based Metal Organic Frameworks: Luminescence, Gas Adsorption, and Antibacterial Studies, Anorg.Allg.Chem., 645(1), 2019, 50-56.

25. LISA, J.W., HEXIANG, D., HIROYASU, F., FELIPE, G., KYLE, E.C., DANI, P., YAGHI, O.M., Synthesis and characterization of metal-organic framework-74 containing 2, 4, 6, 8, and 10 different metals, Inorg.Chem., 53(12), 2014, 5881-5883.

26. BANERJEE, D., KIM, S.J., LI, W., WU, H., LI, J., BORKOWSKI, L.A., PHILIPS, B.L., PARISE, J.B., Synthesis and Structural Characterization of a 3-D Lithium Based Metal- Organic Framework Showing Dynamic Structural Behavior, Cryst.Growth Des., 10(6), 2010, 2801-2805.

27. THIRUMURUGAN, A., TAN, J.C., ANTHONY, K.C., Heterometallic InorganicOrganic Frameworks of Sodium-Bismuth Benzenedicarboxylates, Cryst.Growth Des., 10(4), 2010, 1736-1741.

28. GUL-E-NOOR, F., JEE, B., MENDT, M., HIMSL, D., POEPPL, A., HARTMANN, M., HAASE, J., KRAUTSCHEID, H., BERTMER, M., Formation of Mixed Metal Cu3-x Zn x (btc) 2 Frameworks with Different Zinc Contents: Incorporation of Zn2+ into the Metal-Organic Framework Structure as Studied by Solid-State NMR, J.Phys.Chem.C., 116(39), 2012, 20866-20873.

29. MEIKE, A., ROLAND, S., SILKE, W., MATTHIAS, B., WOLFGANG, K., Synthesis and characterization of bimetallic metal-organic framework $\mathrm{Cu}$-Rus-BTC with HKUST-1 structure, Dalton Trans., 44(5), 2015, 2052-2056.

$\overline{\text { Manuscript received: } 9.07 .2019}$ 